\title{
The Masticatory Contractile Load Induced Expression and Activation of Akt1/PKB $\alpha$ in Muscle Fibers at the Myotendinous Junction within Muscle-Tendon-Bone Unit
}

\author{
Yüksel Korkmaz, ${ }^{1}$ Franz J. Klinz, ${ }^{2}$ Mehrnoush Moghbeli, ${ }^{3}$ Klaus Addicks, ${ }^{2}$ \\ Wolfgang H.-M. Raab, ${ }^{1}$ and Wilhelm Bloch ${ }^{3}$ \\ ${ }^{1}$ Department of Operative Dentistry, Periodontics and Endodontics, Heinrich-Heine-University, 40225 Düsseldorf, Germany \\ ${ }^{2}$ Department I of Anatomy, University of Cologne, 50931 Cologne, Germany \\ ${ }^{3}$ Department of Molecular and Cellular Sports Medicine, German Sports University, 50933 Cologne, Germany
}

Correspondence should be addressed to Wilhelm Bloch,w.bloch@dshs-koeln.de

Received 2 November 2009; Accepted 4 March 2010

Academic Editor: Guy M. Benian

Copyright (C) 2010 Yüksel Korkmaz et al. This is an open access article distributed under the Creative Commons Attribution License, which permits unrestricted use, distribution, and reproduction in any medium, provided the original work is properly cited.

The cell specific detection of enzyme activation in response to the physiological contractile load within muscle-tendon-bone unit is essential for understanding of the mechanical forces transmission from muscle cells via tendon to the bone. The hypothesis that the physiological mechanical loading regulates activation of Akt1/PKB $\alpha$ at Thr308 and at Ser473 in muscle fibers within muscletendon-bone unit was tested using quantitative immunohistochemistry, confocal double fluorescence analysis, and immunoblot analysis. In comparison to the staining intensities in peripheral regions of the muscle fibers, $A k t 1 / \mathrm{PKB} \alpha$ was detected with a higher staining intensity in muscle fibers at the myotendinous junction (MTJ) areas. In muscle fibers at the MTJ areas, Akt1/PKB $\alpha$ is dually phosphorylated at Thr308 and Ser473. The immunohistochemical results were confirmed by immunoblot analysis. We conclude that contractile load generated by masticatory muscles induces local domain-dependent expression of Akt1/PKB $\alpha$ as well as activation by dually phosphorylation at Thr308 and Ser473 in muscle fibers at the MTJ areas within muscle-tendon-bone unit.

\section{Introduction}

The muscle-tendon-bone unit contains myocytes, fibroblasts, nerve fibers, blood vessels, osteoblasts, osteoclasts, osteocytes, and extracellular matrix. The integrity of the muscle-tendon-bone unit is maintained through cell-cell and cell-extracellular matrix interactions. Tendons transmit forces generated from muscle cells at the muscle-tendonjunction (MTJ) to bone cells. During a signal transmission in cells of the muscle-tendon-bone unit, extracellular matrix, cell membrane, cytoskeleton, nuclear protein matrix, and gene expression are altered by mechanical loading in muscle cells and transmitted further to cells of the tendon-bone unit in autocrine as well as paracrine manner [1].

The serine/threonine protein kinase $\mathrm{B}(\mathrm{Akt} / \mathrm{PKB})$ is a downstream effector of phosphatidylinositol 3-kinase (PI3K) and a regulator of a variety of cellular processes, including transcription, survival, proliferation, growth, and metabolism [2,3]. In mammals, Akt/PKB is expressed ubiquitously with three isoforms: Akt $1 / \mathrm{PKB} \alpha$, Akt $2 / \mathrm{PKB} \beta$, and Akt3/PKB $\gamma$ [4]. The activation of PI3K through binding of a growth factor to a receptor tyrosine kinase $[5,6]$ converts the membrane-bound plasma membrane lipid phosphatidylinositol 4,5-bisphosphate $\left(\mathrm{PI}(4,5) \mathrm{P}_{2}\right)$ to phosphatidylinositol 3,4,5-trisphosphate $\left(\mathrm{PI}(3,4,5) \mathrm{P}_{3}\right)[6,7] . \mathrm{PI}(3,4,5) \mathrm{P}_{3}$ anchors Akt/PKB to the plasma membrane and induces a conformational change, which results in the phosphorylation of Akt/PKB. Phosphorylated amino acid residues include the threonine residue Thr308 in the kinase catalytic domain and the serine residue Ser473 in the hydrophobic motif of $A k t 1 / \mathrm{PKB} \alpha$ [3]. Full activation of $A k t 1 / \mathrm{PKB} \alpha$ requires phosphorylation of the enzyme at Thr308 and at Ser473 [8]. It is well established that Thr308 is phosphorylated by 3-phosphoinositide-dependent kinase-1 (PDK1) [9]. The 
phosphorylation of Akt1/PKB $\alpha$ at Ser473 is mediated by both mammalian target of rapamycin-rictor complex (mTORC2) [10] and DNA-dependent protein kinase (DNA-PK) [11] depending on type of stimulus.

The knowledge about bone remodelling by mechanical load generated from muscle cells to the bone cells requires understanding of the complete signal transmission between cells of the muscle-tendon-bone unit. However, in contrast to separate studies performed on muscle, tendon, or bone cells, there are no in vivo or in vitro studies about effects of the physiological forces generated by muscle cells and transmitted via tendon to the bone cells in model systems that contain muscle-tendon-bone unit cells.

The activation of $A k t 1 / \mathrm{PKB} \alpha$ is involved in different functions of the muscle, tendon, and bone cells. Akt $1 / \mathrm{PKB} \alpha$ promotes muscle cell differentiation $[12,13]$ and induces muscle hypertrophy [14-16]. In tendon cells, IGF-Idependent activation of Akt1/PKB $\alpha$ prevents apoptosis [17]. The cellular mechanism of the physiological mechanotransduction transmission that regulates $A \mathrm{kt} 1 / \mathrm{PKB} \alpha$ in different cell types of the muscle-tendon-bone unit is unknown. Therefore, the physiological stimuli including mastication contractile-dependent regulation of $A k t 1 / \mathrm{PKB} \alpha$ in different types of cells within muscle-tendon-bone unit remain to be established. In sections of maxilla that contain cells of the muscle-tendon-bone unit, the expression, localization, and phosphorylation of $\mathrm{Akt} 1 / \mathrm{PKB} \alpha$ were investigated by quantitative immunohistochemistry using total and phosphospecific Akt1/PKB $\alpha$ Thr308 and Ser473 antibodies. To test the expression of $A k t 1 / \mathrm{PKB} \alpha$ and $\mathrm{p}-\mathrm{Akt} 1 / \mathrm{PKB} \alpha$ Ser 473 in muscle cells at the periphery and at the myotendinous junction (MTJ) areas, immunoblot experiments were performed.

\section{Materials and Methods}

2.1. Reagents and Antibodies. Bovine serum albumin (BSA) was purchased from Sigma (Sigma, St. Louis, MO). Biotinylated goat antirabbit $\operatorname{IgG}$, biotinylated antimouse IgG, normal goat serum (NGS), and Vectastain-ABC Kit were obtained from Vector Laboratories (Burlingame, CA, USA). Rabbit anti-Akt1/PKB $\alpha$ and rabbit antiphosphoAkt1/PKB $\alpha$ (Thr308) polyclonal antibodies were purchased from Upstate Biotechnology (Lake Placid, NY, USA). Mouse antiphospho-Akt1/PKB $\alpha$ (Ser473) monoclonal antibody was obtained from Cell Signaling Technology (Beverly, MA, USA). Cy3-conjugated goat antirabbit IgG was from Jackson ImmunoResearch Labs. (West Grove, PA). DyLight 488conjugated NeutrAvidin (Pierce Biotechnology, Rockford, IL) was ligand for biotinylated antimouse IgG. DRAQ5 (Axorra, San Diego, CA) was used as a fluorescent DNA stain.

It is known that the antibody specificity is best determined by immunoblot techniques [18]. The specificities of Akt1/PKB $\alpha$, p-Akt1/PKB $\alpha$ at Thr308 and at Ser473 were determined by immunoblot analysis [19].

2.2. Tissue Preparation. Male Wistar rats $(n=12 ; 3$ months old, weighing $280-300 \mathrm{~g}$ ) were fixed by transcardiac perfusion with $4 \%$ paraformaldehyde and $0.2 \%$ picric acid $\mathrm{pH}$
7.4, under deep anesthesia with a mixture of Ketamine $(100 \mathrm{mg} / \mathrm{kg})$ and Xylazine $(5 \mathrm{mg} / \mathrm{kg})$. The jaws were dissected with masticatory muscle using forceps and the samples demineralized in $4 \mathrm{~N}$ formic acid at $4^{\circ} \mathrm{C}$ for 14 days.

For immunoblot experiments, after sacrifice of animals $(n=3)$ by exposure to a rising concentration of $\mathrm{CO}_{2}$ inhalation, the masticatory muscle tissues were immediately cut into two areas as peripheral area and muscle near at the MTJ area by aid of an operating microscope.

Animal handling procedures were carried out in compliance with guidelines of the local animal ethics committee.

2.3. Immunohistochemistry. In the free floating sections, endogenous peroxidases were inhibited with $0.3 \% \mathrm{H}_{2} \mathrm{O}_{2}$. To block nonspecific bindings, sections were treated with $1 \%$ BSA $+10 \%$ NGS. Thereafter, sections were incubated for 48 hours at $4^{\circ} \mathrm{C}$ with anti-Akt1/PKB $\alpha$, anti-p-Akt1/PKB $\alpha$ Thr308, and anti-p-Akt1/PKB $\alpha$ Ser473 at $1: 800$ for each antibody. Then the sections were incubated with biotinconjugated goat antirabbit IgG $(1: 500)$ and biotinylated antimouse $\operatorname{IgG}(1: 500)$. The sections were incubated with avidin-biotin-peroxidase complex $(1: 100)$ for 1 hour and the immunohistochemical reaction was visualized with $0.05 \% 3,3^{\prime}$-diaminobenzidine tetrahydrochloride (Sigma, St. Louis, MO, USA) in $0.05 \mathrm{M}$ Tris-HCl buffer, $\mathrm{pH} 7.6$ containing $0.01 \% \mathrm{H}_{2} \mathrm{O}_{2}$ and $0.01 \%$ nickel ammonium sulphate. Control experiments were performed by omission of the primary or secondary antibodies from incubations as well as by immunoblot analysis.

\subsection{Double-Immunofluorescence Labelling and Confocal} Microscopy. The free floating sections were incubated with mouse anti-p-Akt1/PKB $\alpha$ Ser473 (1:800) for 24 hours at $4^{\circ} \mathrm{C}$. The sections were incubated with biotinylated goat antimouse IgG $(1: 1000)$ and with the DyLight 488 -conjugated NeutrAvidin $(1: 200)$ for 1 hour at RT, respectively. Then, the sections were incubated with p-Akt/PKB Thr308 for 24 hours at $4^{\circ} \mathrm{C}$. The sections were incubated with Cy3conjugated goat antirabbit IgG $(1: 1000)$ for 1 hour at RT in the dark. Staining of nuclear DNA staining was done using DRAQ5 (1:2000) as described earlier [20]. Control experiments were performed in separate incubations by omission of the primary or secondary antibodies. Images of double immunofluorescence experiments were acquired on an LSM510 confocal microscope (Zeiss, Oberkochem, Germany).

2.5. Immunoblot. The tissues were homogenized in a buffer containing proteinase and phosphatase inhibitors. Protein concentrations were determined by the method of Bradford. Protein samples were separated on an SDS-PAGE gradient gel and transferred to PVDF filters. The blots were blocked with $5 \%$ dry milk for 1 hour and incubated with $A k t 1 / \mathrm{PKB} \alpha$ $(1: 1000)$ and with p-Akt1/PKB $\alpha \operatorname{Ser} 473(1: 1000)$ antibodies overnight at $4^{\circ} \mathrm{C}$. The blots were incubated with HRPconjugated secondary antibody $(1: 5000)$ for 1 hour at RT and subsequently developed with enhanced chemiluminescence assay for 1 minute. 
2.6. Densitometry of the Immunohistochemical and Immunoblot Results. The immunostained sections were captured with a CCD camera and the staining intensities of the antibodies in muscle cells were measured in a blinded fashion. In immunoblot, the films were scanned, and the density of the specific immunoreactive bands was measured and normalized with an internal loading $\beta$-actin control.

2.7. Statistical Analysis. Data are represented as mean \pm SD. Differences between groups were compared using Student's $t$-test or one-way ANOVA with Bonferroni post-hoc test used to compare multiple means. The criterion for statistical significance was considered at a $P$ value $<.05$.

\section{Results}

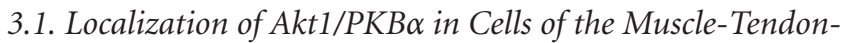
Bone Unit. Total (t) Akt1/PKB $\alpha$ (nonphosphorylated and phosphorylated) was detected in a moderate staining in the peripheral part of muscle fibers (Figures 1(a) and 1(b)). In comparison to the staining intensities in peripheral areas (Figures $1(\mathrm{a})$ and $1(\mathrm{~g})$ ), there was an increase in total Akt $1 / \mathrm{PKB} \alpha$ staining at the area near to the myotendinous junction (MTJ) in the muscle fibers (Figures 1(a), 1(b), and $1(\mathrm{~g}))$. Immunohistochemical control incubations without primary or secondary antibodies resulted in the disappearance of the specific reaction product (data not shown).

3.2. Localization of $p-A k t 1 / P K B \alpha$ Thr308 and Ser473 in Muscle Fibers Near the Muscle-Tendon-Bone Unit. In comparison to the very weak staining intensities of p-Akt1/PKB $\alpha$ Thr308 in the periphery of muscle fibers (Figures 1(c), 1(d), and $1(\mathrm{~g})$ ) within muscle-tendon-bone unit, phosphorylation at Thr308 was detected with a higher staining intensity in muscle fibers near to the MTJ areas (Figures 1(c), 1(d), and $1(\mathrm{~g}))$. In the periphery of muscle fibers, the staining intensity of the $\mathrm{p}-\mathrm{Akt} \mathrm{t} / \mathrm{PKB} \alpha$ Ser 473 residue was very weakly (Figures 1(e), 1(f), and 1(g)). Phosphorylation at Ser473 was detected with a higher staining intensity nearby the MTJ (Figures 1(e), 1(f), and $1(\mathrm{~g})$ ). In all instances, the peripheral parts of the muscle fibers were very weakly positive or almost negative for $\mathrm{p}-\mathrm{Akt} 1 / \mathrm{PKB} \alpha \mathrm{Thr} 308$ (Figures $1(\mathrm{c})$ and $1(\mathrm{~d})$ ) as well Ser473 (Figures 1(e) and 1(f)). The immunohistochemical controls resulted in the disappearance of the signal product (data not shown). The specificity of antibodies against $\mathrm{Akt} 1 / \mathrm{PKB} \alpha, \mathrm{Akt} 1 / \mathrm{PKB} \alpha$ phosphorylated at Thr308 and Ser473 was confirmed by immunoblot analysis [19].

3.3. Immunohistochemical Colocalization of $p-A k t 1 / P K B \alpha$ Thr308 and Ser473 in Muscle Cells Nearby the MTJ. To determine whether mastication forces could stimulate full activation of $\mathrm{Akt} 1 / \mathrm{PKB} \alpha$ in muscle fibers, double immunofluorescence analyses of Akt1/PKB $\alpha$ phosphorylated at Ser473 and at Thr308 were performed.

The nuclei in cells of the muscle and tendon were visualized by staining of DNA with DRAQ5 (blue color; Figure 2(a)). Immunohistochemical localization of green reaction product for Akt phosphorylated at Ser473 was detected only in cross sectioned muscle cells at MTJ (Figure 2(b)). The cross sectioned muscle fibers revealed also a strong red staining for $\mathrm{Akt} 1 / \mathrm{PKB} \alpha$ phosphorylated at Thr308 (Figure 2(c)). In muscle fibers at the MTJ areas, the colocalization of p-Akt1/PKB $\alpha$ phosphorylated at Thr308 and at Ser473 was detected by yellow staining (Figure 2(d)). The immunohistochemical controls resulted in the disappearance of the specific immunofluorescence signal (data not shown).

3.4. Immunoblot Analysis. Results demonstrating higher immunohistochemical staining intensities of $\mathrm{t}-\mathrm{Akt} 1 / \mathrm{PKB} \alpha$ (Figures 1(a), 1(b), and 1(g)) and p-Akt1/PKB $\alpha$ Ser473 in muscle fibers nearby the MTJ areas were confirmed by immunoblot analysis. Immunoblot results for $A k t 1 / \mathrm{PKB} \alpha$ are presented in Figure 3 and for p-Akt1/PKB $\alpha$ Ser 473 in Figure 4.

In comparison to the staining intensity in periphery of muscle fibers, t-Akt1/PKB $\alpha$ was detected as a band of approximately $60 \mathrm{kDa}$ with higher staining intensity in muscle cells nearby MTJ areas (Figure 3). The staining intensity of the p-Akt1/PKB $\alpha$ Ser 473 residue was very weak at the peripheral part of muscle, while a characteristic band of approximately at $60 \mathrm{kDa}$ for p-Akt1/PKB $\alpha$ Ser473 was detected with a strong staining intensity at the area nearby MTJ (Figure 4). As a loading control muscle lysates were analyzed by immunoblot with an antibody against $\beta$-actin (data not shown).

\section{Discussion}

Under cell culture conditions, the importance of physical stresses on a variety of cellular activities has been examined only in a single cell type, including myocytes, fibroblasts, osteoblasts, and osteoclasts. Similarly, the mechanical loads on muscle fibers, tendon, and bone cells within the muscletendon unit were separately investigated. In comparison to studies only in muscle, tendon, or in bone cells, we performed a quantitative immunohistochemical analysis in sections, which allows localization of the functional Akt $1 / \mathrm{PKB} \alpha$ protein in all cells within the muscle-tendonbone unit. In this model, muscle contractile activity should be generated by physiological mastication. Compared to the periphery of the muscle fibers within muscle-tendonbone unit, the protein level of the $A k t 1 / \mathrm{PKB} \alpha$ and the phosphorylation of Akt1/PKB $\alpha$ at Thr308 and Ser473 were significantly higher at the MTJ area.

Tendon cells connect muscle fibers to bones and transmit forces developed by muscle fibers to the bone cells. Thus, muscle fibers apply forces to the bone cells via tendon cells, which arise from a specialized region called the MTJ. In the MTJ, myofibrils and collagen fibers overlap, forming longitudinal infoldings $[21,22]$. In comparison to end-toend contact, these overlapping contacts between muscle cells and collagen fibers increase the strength of the junction because cell membranes support shear loads better than the tensile loads $[21,22]$. In muscle fiber region nearby MTJ, the physiological mastication stimuli may induce expression 


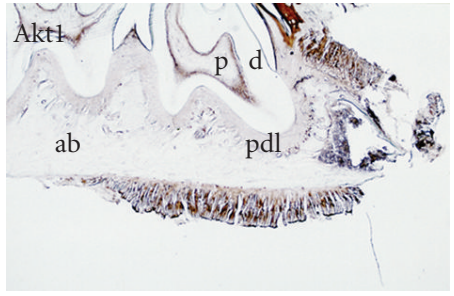

(a)

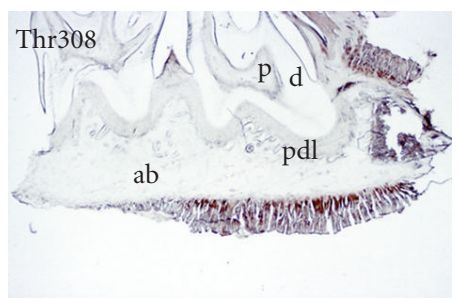

(c)

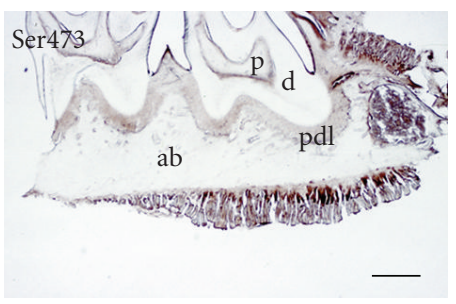

(e)

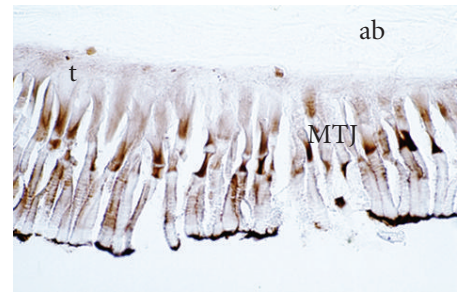

(b)

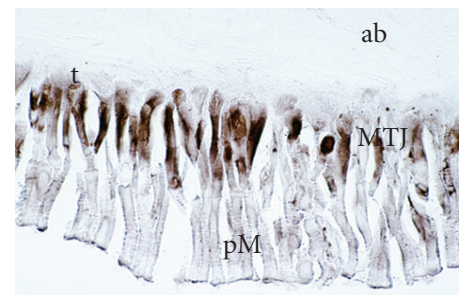

(d)

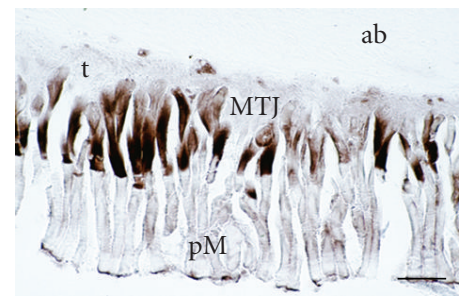

(f)

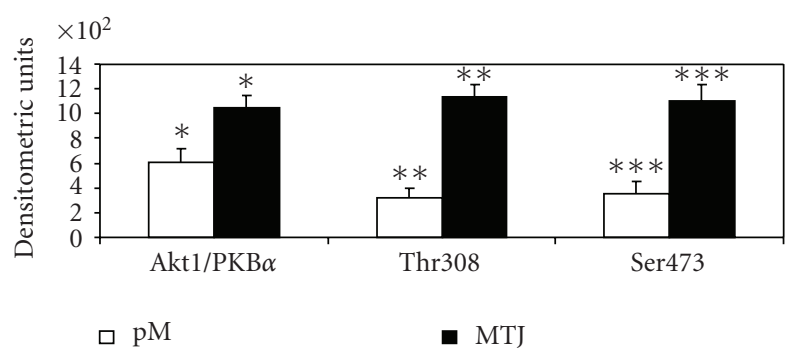

(g)

FIgURE 1: The constitutive localization of the $\mathrm{t}-\mathrm{Akt} 1 / \mathrm{PKB} \alpha$, phosphorylation of $\mathrm{t}-\mathrm{Akt} 1 / \mathrm{PKB} \alpha$ at Thr308 and at Ser473 in muscle fibers within muscle-tendon-bone unit. In comparison to the staining of t-Akt1/PKB $\alpha$ (a, b), p-Akt1/PKB $\alpha$ Thr308 (c, d) and Ser473 (e, f) in the peripheral muscle fibers, $\mathrm{t}-\mathrm{Akt1} / \mathrm{PKB} \alpha$ (b, MTJ), phosphorylation of Akt1/PKB $\alpha$ at Thr308 (d, MTJ) and at Ser473 (f, MTJ) were detected with higher staining intensities in muscle fibers at the myotendinous junction (MTJ) area. The staining intensity of $A k t 1 / \mathrm{PKB} \alpha$ in peripheral muscle fibers (b, 602.70 \pm 117.05$)$ was weakly compared to those in the area near to the MTJ (b, 1050.63 \pm 91.68$)$. In comparison to the staining intensity of the $\mathrm{p}-\mathrm{Akt} 1 / \mathrm{PKB} \alpha \mathrm{Thr} 308$ in peripheral muscle fibers (d, $319.76 \pm 74.57)$, the staining intensity of $\mathrm{p}$-Akt1/PKB $\alpha$ Thr308 was higher in muscle fibers near to the MTJ areas ( $\mathrm{d}, 1138.85 \pm 98.99)$. The staining intensity of p-Akt1/PKB $\alpha$ Ser473 in muscle fibers at the MTJ areas (f, $351.65 \pm 104.63$ ) was greater than staining intensity of Ser473 in peripheral muscle areas (f, 1099.70 \pm 135.93$)$. Data are mean $\pm \mathrm{SD} ; n=6$; significant differences were considered at a $P$ value $<.05$. MTJ $=$ myotendinous junction, $\mathrm{pM}=$ peripheral muscle fibers, ab $=$ alveolar bone, pdl = periodontal ligament, $\mathrm{p}=$ pulpa, $\mathrm{d}=$ dentin. Bars: $640 \mu \mathrm{m}$ for (a), (c), (e), $80 \mu \mathrm{m}$ for (b), (d), and (f).

of $\mathrm{Akt} 1 / \mathrm{PKB} \alpha$ by nuclear domain regulation as well as by phosphorylation of the enzyme at Thr308 and at Ser473.

In response to physiological masticatory mechanical loading, Akt $1 / \mathrm{PKB} \alpha$ was detected in higher protein levels in muscle fibers nearby MTJ areas. The higher staining intensity of the t-Akt1/PKB $\alpha$ at MTJ may be explained by local regulation of $\mathrm{Akt} 1 / \mathrm{PKB} \alpha$ in different nuclear domains during transmission of forces generated by physiological mastication stimuli in muscle cells. In multinucleated muscle fibres, it was reported that each nucleus is able to regulate protein biosynthesis in a local domain-dependent manner $[23,24]$. It can be speculated that the higher number of nuclear domains present in muscle fibers nearby MTJ [25] responds to mechanical stimulation of mastication by higher production of $A k t 1 / \mathrm{PKB} \alpha$ than nuclear domains in peripheral muscle areas.

In the consecutive muscle-tendon-bone unit sections, Thr308 and Ser473 phosphorylation sites of Akt1/PKB $\alpha$ were 


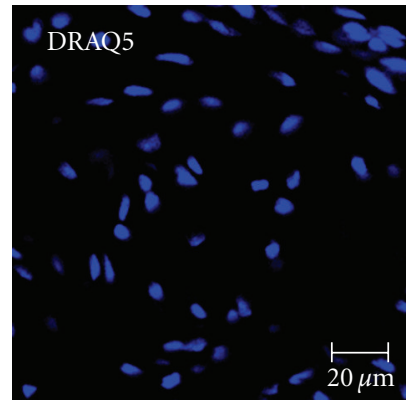

(a)

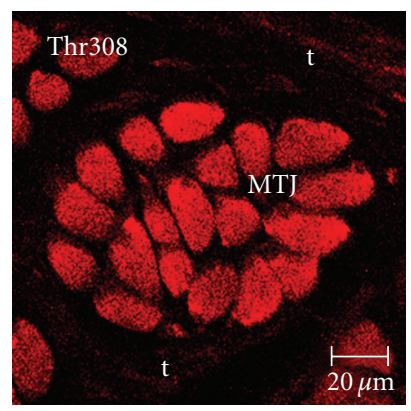

(c)

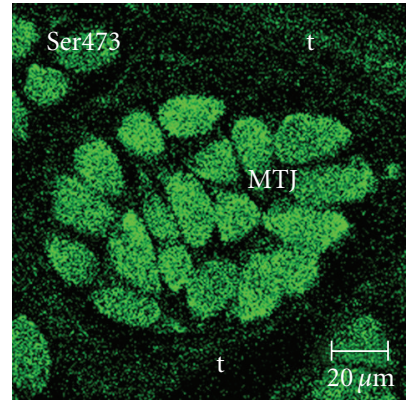

(b)

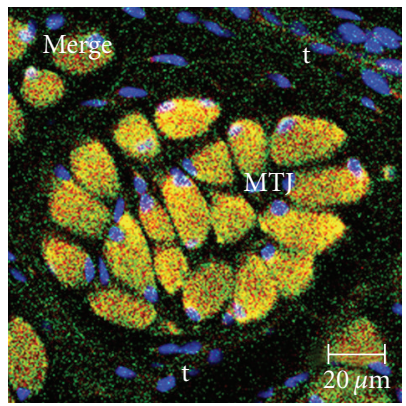

(d)

Figure 2: Immunofluorescence colocalization of Akt1/PKB $\alpha$ phosphorylated at Ser473 and at Thr308 in muscle fibers at the myotendinous areas. The nuclei in muscle fibers and tendocyte were visualized by staining of DNA with DRAQ5 (a, blue). The p-Akt1/PKB $\alpha$ Ser473 (b, green) was localized in across sectioned muscle fibers at the MTJ. In muscle fibers at the MTJ, p-Akt1/PKB $\alpha$ Thr308 (c, red) was identified. In same muscle fibers, $\mathrm{p}-\mathrm{Akt} 1 / \mathrm{PKB} \alpha$ Ser473 and Thr308 were colocalized ( $\mathrm{d}$, yellow). The tendon cells were negative for localizations of Ser473 as well as of Thr308. MTJ $=$ myotendinous junction, $\mathrm{t}=$ tendon. Bar: $(\mathrm{a})-(\mathrm{d})=20 \mu \mathrm{m}$.

detected with a higher staining intensity in muscle fibers at MTJ area compared to the peripheral muscle fiber areas. Therefore, we have presumed that Akt1/PKB $\alpha$ may be dually phosphorylated in muscle fibers at MTJ areas. Full activation of Akt $1 / \mathrm{PKB} \alpha$ requires dually phosphorylation of the enzyme at Thr308 and at Ser473 [26, 27]. More recently, knockout experiments in murine embryonic fibroblast came to the conclusion that Akt/PKB monophosphorylated at Thr308 was able to activate several downstream targets [8]. In muscle cells at the MTJ areas, we have detected a colocalization of Thr308 and at Ser473. Our data indicate that full activation of Akt1/PKB $\alpha$ by phosphorylation at Thr308 and Ser473 is necessary for downstream signal transduction in muscle cells at the MTJ areas.

For skeletal muscle cells, it was shown by in vitro [28] and in vivo experiments $[16,29,30]$ that constitutive activation of Akt $1 / \mathrm{PKB} \alpha$ induces hypertrophy. This effect of $A k t 1 / \mathrm{PKB} \alpha$ in skeletal muscle is also supported by the finding that $A k t 1 / \mathrm{PKB} \alpha$ inhibits atrophy in vitro as well as in vivo $[31,32]$. In addition, mice lacking $A k t 1 / \mathrm{PKB} \alpha$ show a decrease in muscle size compared with wild-type $[15,33]$. Under consideration of these data, it is apparently that physiological constitutive phosphorylation of Akt $1 / \mathrm{PKB} \alpha$ in skeletal masticatory muscle cells at the MTJ areas may be involved in the muscle cell hypertrophy and muscle cell survival.
The skeletal muscle fibers are classified in type I (slowtwitch oxidative) and in type II (fast-twitch glycolytic) fibers [33]. Fast-twitch fibers are further subdivided into two general groups, the fast-twitch oxidative type IIA and fasttwitch glycolytic type IIB fibers [33]. Masticatory muscles are composed of a heterogeneous population of fiber types that vary according to their contractile properties $[34,35]$. In the masseter, it was described that the type I fibers were absent [36]. The IIA and IIB fibers were distributed differently between the superior and inferior regions of the masseter [34-36]. In the deep masseter, the highest proportion of type IIB fibers is distributed [36]. The cross-sectional areas of type IIB fibers were the largest, followed by the type IIX and IIA fibers [36]. From our results, it may be suggested that physiological exercise represents a mechanism by which mastication in vivo induces simultaneous phosphorylation of Akt1/PKB at Ser 473 and Thr308 in both fast-twitch muscle fiber types at the MTJ.

It was described that the muscle fiber type is regulated by calcineurin and the Ras-MAPK signaling, while fiber size is regulated by the PI3K-Akt/PKB-mTOR signaling $[30,37,38]$. The mTOR has been implicated in skeletal muscle hypertrophy during overload, and pharmacological inhibition of mTOR prevents overload-induced hypertrophy in both type I and type II of muscle fibers [29]. These results indicate that the hypertrophic effect on muscle 

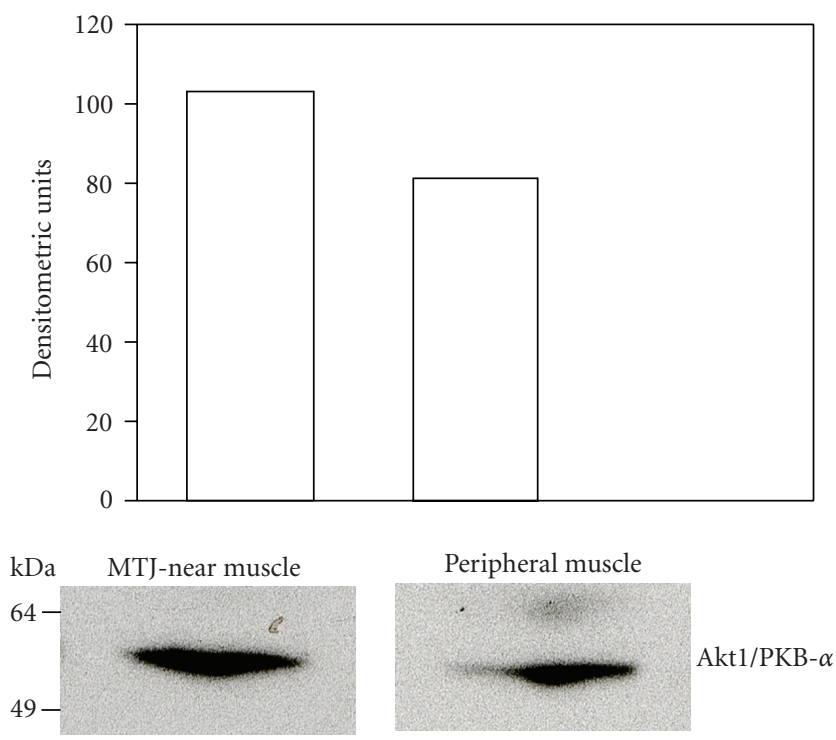

FIGURE 3: Immunoblot analysis of Akt/PKB in peripheral muscle fibers and in muscle cells near to the myotendinous areas. In peripheral masticatory muscle fibers and masticatory muscle fibers at MTJ, protein extracts were analyzed by immunoblot analysis using an antibody against $\mathrm{Akt} 1 / \mathrm{PKB} \alpha$. The specific immunoblot bands of approximately $60 \mathrm{kDa}$ identify $\mathrm{Akt} 1 / \mathrm{PKB} \alpha$ in peripheral muscle fibers and in muscle fibers near to the MTJ. The level of $\mathrm{Akt} 1 / \mathrm{PKB} \alpha$ in muscle fibers near to the MTJ was higher than that in peripheral muscle fibers.

fibers by $\mathrm{Akt} 1 / \mathrm{PKB} \alpha$ predominantly occurs through mTOR signaling [30]. Phosphorylation of Akt1/PKB $\alpha$ at Ser473 is mediated by mTORC2 [10]. Therefore, phosphorylation of Akt $1 / \mathrm{PKB} \alpha$ at Ser473 in muscle fibers at MTJ may be an important part of the mechanism by which contraction can activate Akt $1 / \mathrm{PKB} \alpha$ at Ser473 in fast-twitch muscles inducing masticatory muscle hypertrophy at the MTJ areas. However, it must be investigated in further studies if there is a different hypertrophy response in a single muscle fibers in masticatory muscle.

The present finding expands the current knowledge about load dependent muscle response. Beside the fact that contraction may regulate $A k t 1 / \mathrm{PKB} \alpha$ in an intensity, time-, and fiber type-specific manner $[39,40]$, it can be suggested that the response to a mechanical stimuli is inhomogeneous along a single muscle fiber at the activation and expression level. It is known that the loss of teeth and absent physiological masticatory contractile activities lead to a dramatic decrease in muscle cell masses and results especially in a strong atrophy of the alveolar bone [41]. Furthermore, it leads to an alteration of force transmission in the masticatory process [41]. Under consideration that mastication forces and mechanical loading of muscle cells are required for tissue integrity and extracellular matrix metabolism inducing phosphorylation of Akt $1 / \mathrm{PKB} \alpha$ in muscle cells located near to the MTJ within muscle-tendonbone unit, it must be considered that the response is possibly not uniform along the fibres.

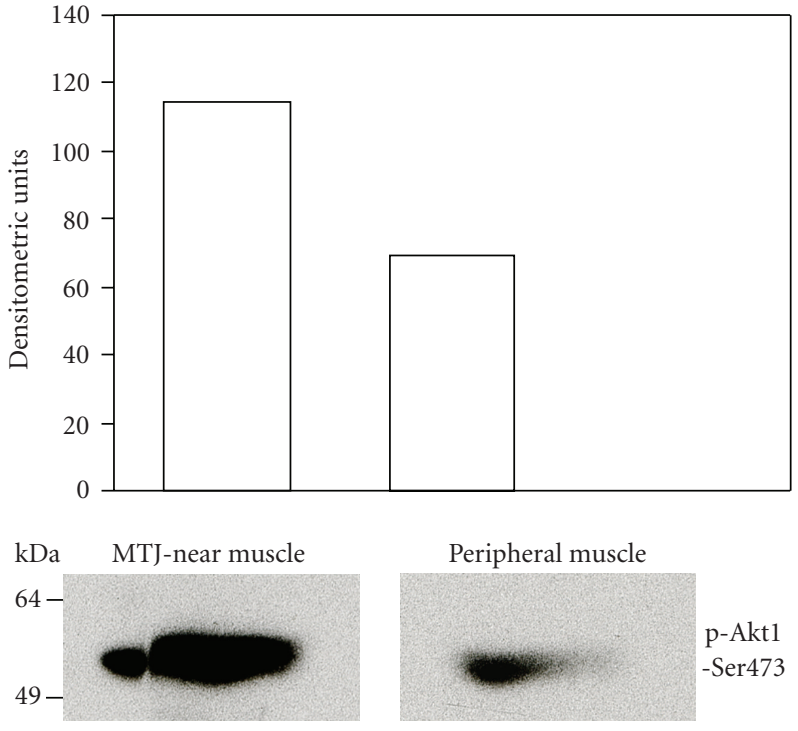

FIGURE 4: Immunoblot analysis of $\mathrm{p}-\mathrm{Akt} 1 / \mathrm{PKB} \alpha \mathrm{Ser} 473$ in peripheral muscle fibers and in muscle fibers near to the myotendinous areas. Protein extracts prepared from peripheral masticatory muscle fibers and masticatory muscle fibers at MTJ were analyzed by immunoblotting using an antibody against $\mathrm{Akt1} / \mathrm{PKB} \alpha$ phosphorylated at Ser473. The weakly phosphorylation of $A k t 1 / \mathrm{PKB} \alpha$ at Ser473 in peripheral muscle fibers is significantly increased in muscle fibers near to the MTJ. A characteristic band almost at $60 \mathrm{kDa}$ for $\mathrm{p}-\mathrm{Akt} 1 / \mathrm{PKB} \alpha$ Ser473 was detectable with a higher staining intensity in muscle fibers near to the MTJ.

\section{Conclusion}

In the muscle-tendon-bone unit, tendons connect masticatory muscle cells to the alveolar bone and transmit masticatory forces generated by muscle cells to the alveolar bone cells. The transmission of this mechanical signal induces a full activation of $\mathrm{Akt} 1 / \mathrm{PKB} \alpha$ by simultaneous phosphorylation of the enzyme at Ser473 and at Thr308 in muscle fibers located near to the MTJ but not at the periphery of the muscle fibers. Therefore, we postulate that inhomogeneous physiological contractile loaddependent activation of the Akt $1 / \mathrm{PKB} \alpha$ phosphorylation at Thr308 and at Ser473 in masticatory muscle cells along the muscle fibers could play a role for the biological response, which can influence the development of muscle dystrophy.

\section{Acknowledgment}

This work contains part of the doctoral thesis of Mehrnoush Moghbeli.

\section{References}

[1] M. Kjær, "Role of extracellular matrix in adaptation of tendon and skeletal muscle to mechanical loading," Physiological Reviews, vol. 84, no. 2, pp. 649-698, 2004. 
[2] D. P. Brazil and B. A. Hemmings, "Ten years of protein kinase B signalling: a hard Akt to follow," Trends in Biochemical Sciences, vol. 26, no. 11, pp. 657-664, 2001.

[3] E. Fayard, L. A. Tintignac, A. Baudry, and B. A. Hemmings, "Protein kinase B/Akt at a glance," Journal of Cell Science, vol. 118 , no. 24, pp. 5675-5678, 2005.

[4] S. R. Datta, A. Brunet, and M. E. Greenberg, "Cellular survival: a play in three Akts," Genes and Development, vol. 13, no. 22, pp. 2905-2927, 1999.

[5] M. P. Scheid and J. R. Woodgett, "Unravelling the activation mechanisms of protein kinase B/Akt," FEBS Letters, vol. 546, no. 1, pp. 108-112, 2003.

[6] D. P. Brazil, Z.-Z. Yang, and B. A. Hemmings, "Advances in protein kinase B signalling: AKTion on multiple fronts," Trends in Biochemical Sciences, vol. 29, no. 5, pp. 233-242, 2004.

[7] L. Stephens, K. Anderson, D. Stokoe, et al., "Prohtein kinase B kinases that mediate phosphatidylinositol 3,4,5trisphosphate-dependent activation of protein kinase B," Science, vol. 279, no. 5351, pp. 710-714, 1998.

[8] E. Jacinto, V. Facchinetti, D. Liu, et al., "SIN1/MIP1 maintains rictor-mTOR complex integrity and regulates Akt phosphorylation and substarte specificity," Cell, vol. 127, no. 1, pp. 125137, 2006.

[9] D. R. Alessi, M. Deak, A. Casamayor, et al., "3-Phosphoinositide-dependent protein kinase-1 (PDK1): structural and functional homology with the Drosophila DSTPK61 kinase," Current Biology, vol. 7, no. 10, pp. 776-789, 1997.

[10] D. D. Sarbassov, D. A. Guertin, S. M. Ali, and D. M. Sabatini, "Phosphorylation and regulation of Akt/PKB by the rictormTOR complex," Science, vol. 307, no. 5712, pp. 1098-1101, 2005.

[11] J. Feng, J. Park, P. Cron, D. Hess, and B. A. Hemmings, "Identification of a PKB/Akt hydrophobic motif Ser-473 kinase as DNA-dependent protein kinase," Journal of Biological Chemistry, vol. 279, no. 39, pp. 41189-41196, 2004.

[12] E. M. Wilson and P. Rotwein, "Selective control of skeletal muscle differentiation by Akt1," Journal of Biological Chemistry, vol. 282, no. 8, pp. 5106-5110, 2007.

[13] P. Rotwein and E. M. Wilson, "Distinct actions of Aktl and Akt2 in skeletal muscle differentiation," Journal of Cellular Physiology, vol. 219, no. 2, pp. 503-511, 2009.

[14] D. J. Glass, "Signalling pathways that mediate skeletal muscle hypertrophy and atrophy," Nature Cell Biology, vol. 5, no. 2, pp. 87-90, 2003.

[15] X.-D. Peng, P.-Z. Xu, M.-L. Chen, et al., "Dwarfism, impaired skin development, skeletal muscle atrophy, delayed bone development, and impeded adipogenesis in mice lacking Akt1 and Akt2," Genes and Development, vol. 17, no. 11, pp. 1352$1365,2003$.

[16] K.-M. V. Lai, M. Gonzalez, W. T. Poueymirou, et al., "Conditional activation of Akt in adult skeletal muscle induces rapid hypertrophy," Molecular and Cellular Biology, vol. 24, no. 21, pp. 9295-9304, 2004.

[17] A. Scott, K. M. Khan, and V. Duronio, "IGF-I activates PKB and prevents anoxic apoptosis in Achilles tendon cells," Journal of Orthopaedic Research, vol. 23, no. 5, pp. 1219-1225, 2005.

[18] R. W. Burry, "Specificity controls for immunocytochemical methods," Journal of Histochemistry and Cytochemistry, vol. 48, no. 2, pp. 163-165, 2000.

[19] H.-V. Wang, L.-W. Chang, K. Brixius, et al., "Integrin-linked kinase stabilizes myotendinous junctions and protects muscle from stress-induced damage," Journal of Cell Biology, vol. 180, no. 5, pp. 1037-1049, 2008.
[20] Y. Korkmaz, W. Bloch, F.-J. Klinz, et al., "The constitutive activation of extracellular signal-regulated kinase 1 and 2 in periodontal ligament nerve fibers," Journal of Periodontology, vol. 80, no. 5, pp. 850-859, 2009.

[21] J. G. Tidball, "Force transmission across muscle cell membranes," Journal of Biomechanics, vol. 24, supplement 1, pp. 43-52, 1991.

[22] B. M. Jockusch, P. Bubeck, K. Giehl, et al., "The molecular architecture of focal adhesions," Annual Review of Cell and Developmental Biology, vol. 11, pp. 379-416, 1995.

[23] Z. W. Hall and E. Ralston, "Nuclear domains in muscle cells," Cell, vol. 59, no. 5, pp. 771-772, 1989.

[24] K. Gundersen and J. C. Bruusgaard, "Nuclear domains during muscle atrophy: nuclei lost or paradigm lost?" Journal of Physiology, vol. 586, no. 11, pp. 2675-2681, 2008.

[25] J. C. Bruusgaard, K. Liestol, M. Ekmark, K. Kollstad, and K. Gundersen, "Number and spatial distribution of nuclei in the muscle fibres of normal mice studied in vivo," Journal of Physiology, vol. 551, no. 2, pp. 467-478, 2003.

[26] M. P. Scheid, P. A. Marignani, and J. R. Woodgett, "Multiple phosphoinositide 3-kinase-dependent steps in activation of protein kinase B," Molecular and Cellular Biology, vol. 22, no. 17, pp. 6247-6260, 2002.

[27] A. Toker and A. C. Newton, "Akt/protein kinase B is regulated by autophosphorylation at the hypothetical PDK-2 site," Journal of Biological Chemistry, vol. 275, no. 12, pp. 8271$8274,2000$.

[28] A. Takahashi, Y. Kureishi, J. Yang, et al., "Myogenic Akt signaling regulates blood vessel recruitment during myofiber growth," Molecular and Cellular Biology, vol. 22, no. 13, pp. 4803-4814, 2002.

[29] S. C. Bodine, T. N. Stitt, M. Gonzalez, et al., "Akt/mTOR pathway is a crucial regulator of skeletal muscle hypertrophy and can prevent muscle atrophy in vivo," Nature Cell Biology, vol. 3, no. 11, pp. 1014-1019, 2001.

[30] G. Pallafacchina, E. Calabria, A. L. Serrano, J. M. Kalhovde, and S. Schiaffino, "A protein kinase B-dependent and rapamycin-sensitive pathway controls skeletal muscle growth but not fiber type specification," Proceedings of the National Academy of Sciences of the United States of America, vol. 99, no. 14, pp. 9213-9218, 2002.

[31] M. Sandri, C. Sandri, A. Gilbert, et al., "Foxo transcription factors induce the atrophy-related ubiquitin ligase atrogin-1 and cause skeletal muscle atrophy," Cell, vol. 117, no. 3, pp. 399-412, 2004.

[32] T. N. Stitt, D. Drujan, B. A. Clarke, et al., "The IGF-1/PI3K/ Akt pathway prevents expression of muscle atrophy-induced ubiquitin ligases by inhibiting FOXO transcription factors," Molecular Cell, vol. 14, no. 3, pp. 395-403, 2004.

[33] W. S. Chen, P.-Z. Xu, K. Gottlob, et al., "Growth retardation and increased apoptosis in mice with homozygous disruption of the Aktl gene," Genes and Development, vol. 15, no. 17, pp. 2203-2208, 2001.

[34] J. A. M. Korfage, J. H. Koolstra, G. E. J. Langenbach, and T. M. G. J. van Eijden, "Fiber-type composition of the human jaw muscles-(part 1) origin and functional significance of fibertype diversity," Journal of Dental Research, vol. 84, no. 9, pp. 774-783, 2005.

[35] J. A. M. Korfage, J. H. Koolstra, G. E. J. Langenbach, and T. M. G. J. van Eijden, "Fiber-type composition of the human jaw muscles-(part 2) role of hybrid fibers and factors responsible for inter-individual variation," Journal of Dental Research, vol. 84, no. 9, pp. 784-793, 2005. 
[36] R. Sano, E. Tanaka, J. A. M. Korfage, et al., "Heterogeneity of fiber characteristics in the rat masseter and digastric muscles," Journal of Anatomy, vol. 211, no. 4, pp. 464-470, 2007.

[37] M. Murgia, A. L. Serrano, E. Calabria, G. Pallafacchina, T. Lomo, and S. Schiaffino, "Ras is involved in nerve-activitydependent regulation of muscle genes," Nature Cell Biology, vol. 2, no. 3, pp. 142-147, 2000.

[38] A. L. Serrano, M. Murgia, G. Pallafacchina, et al., "Calcineurin controls nerve activity-dependent specification of slow skeletal muscle fibers but not muscle growth," Proceedings of the National Academy of Sciences of the United States of America, vol. 98, no. 23, pp. 13108-13113, 2001.

[39] K. Sakamoto, M. F. Hirshman, W. G. Aschenbach, and L. J. Goodyear, "Contraction regulation of Akt in rat skeletal muscle," Journal of Biological Chemistry, vol. 277, no. 14, pp. 11910-11917, 2002.

[40] K. Sakamoto, W. G. Aschenbach, M. F. Hirshman, and L. J. Goodyear, "Akt signaling in skeletal muscle: regulation by exercise and passive stretch," American Journal of Physiology, vol. 285, no. 5, pp. E1081-E1088, 2003.

[41] C. Field, Q. Li, W. Li, and M. Swain, "Influence of tooth removal on mandibular bone response to mastication," Archives of Oral Biology, vol. 53, no. 12, pp. 1129-1137, 2008. 

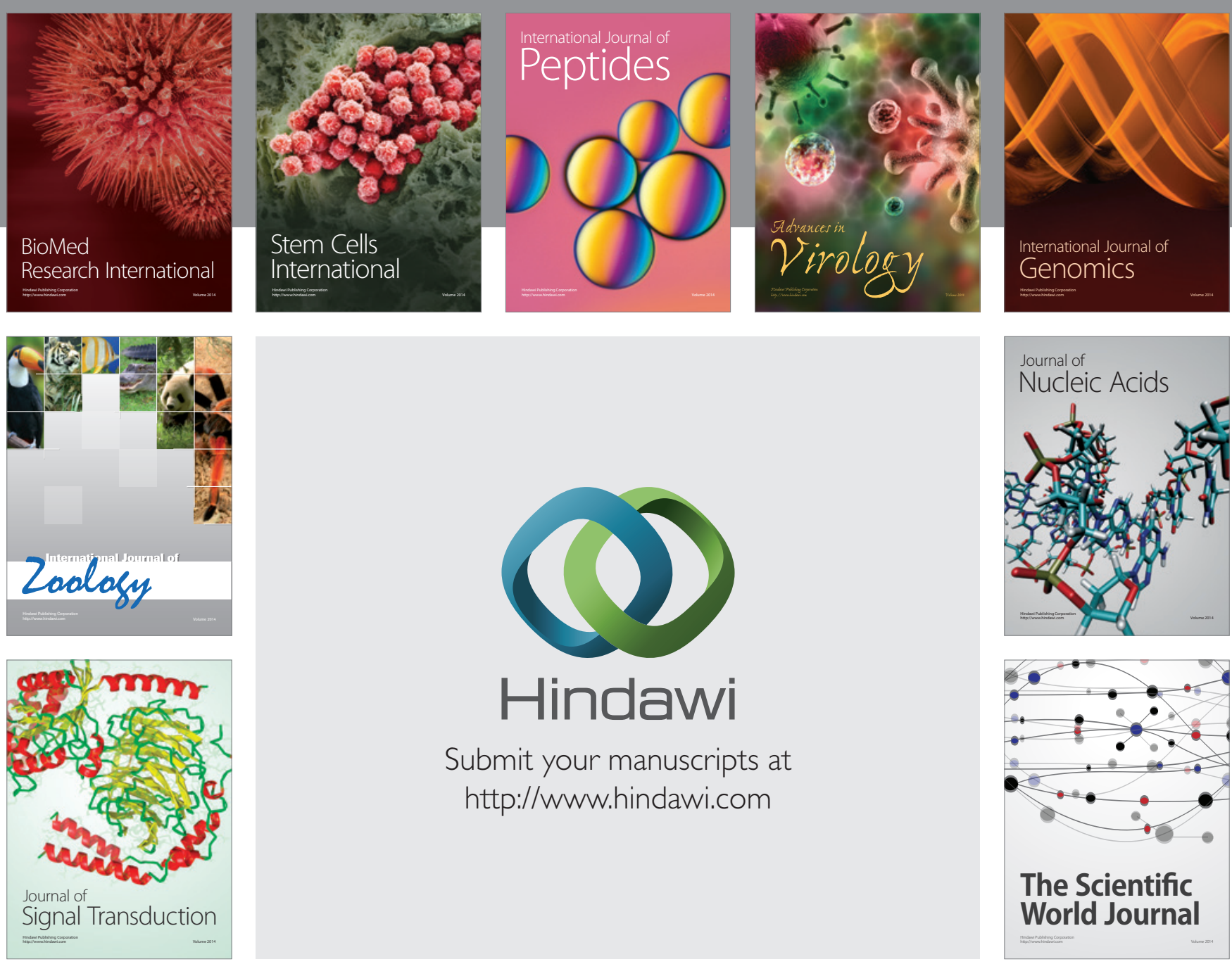

Submit your manuscripts at

http://www.hindawi.com
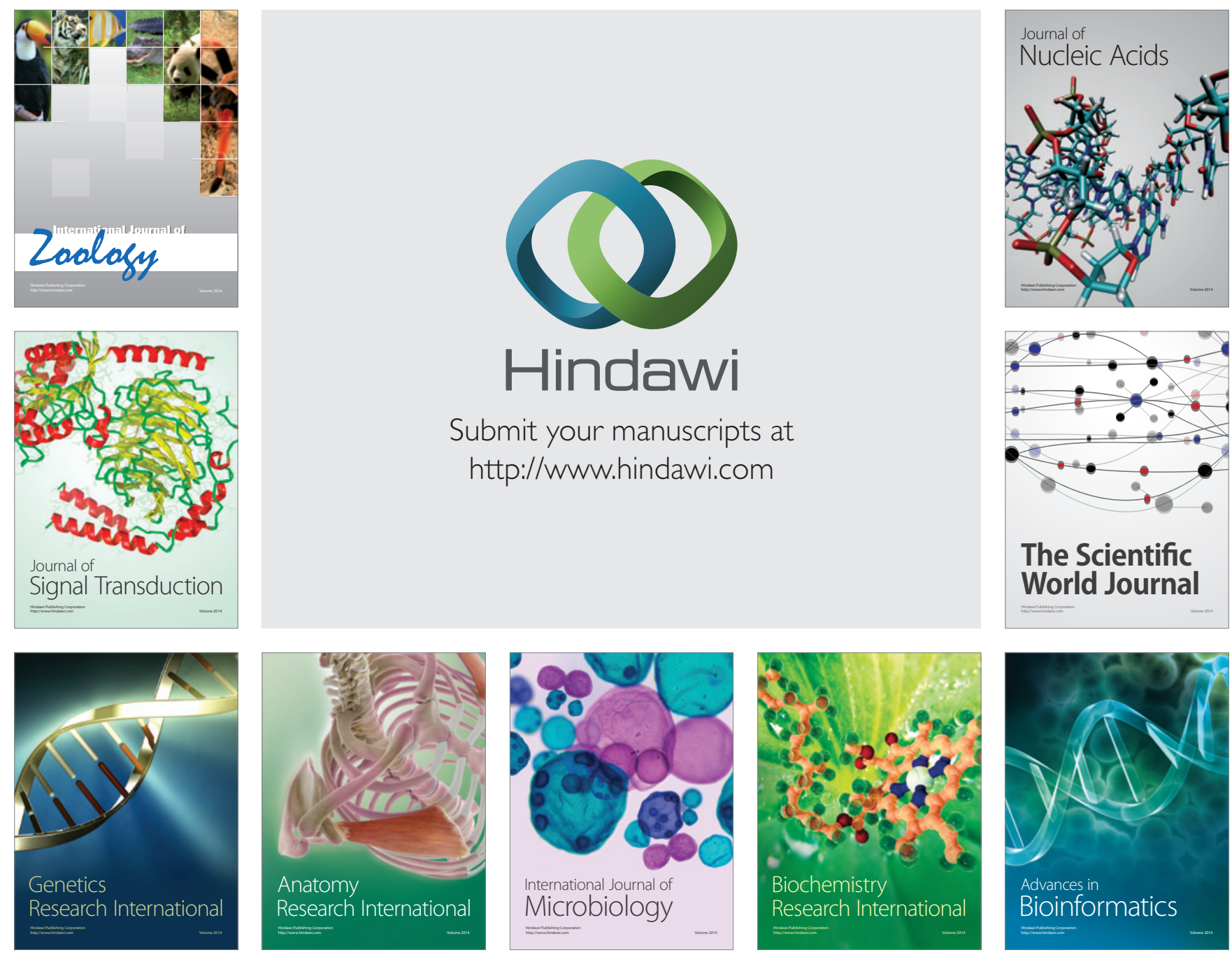

The Scientific World Journal
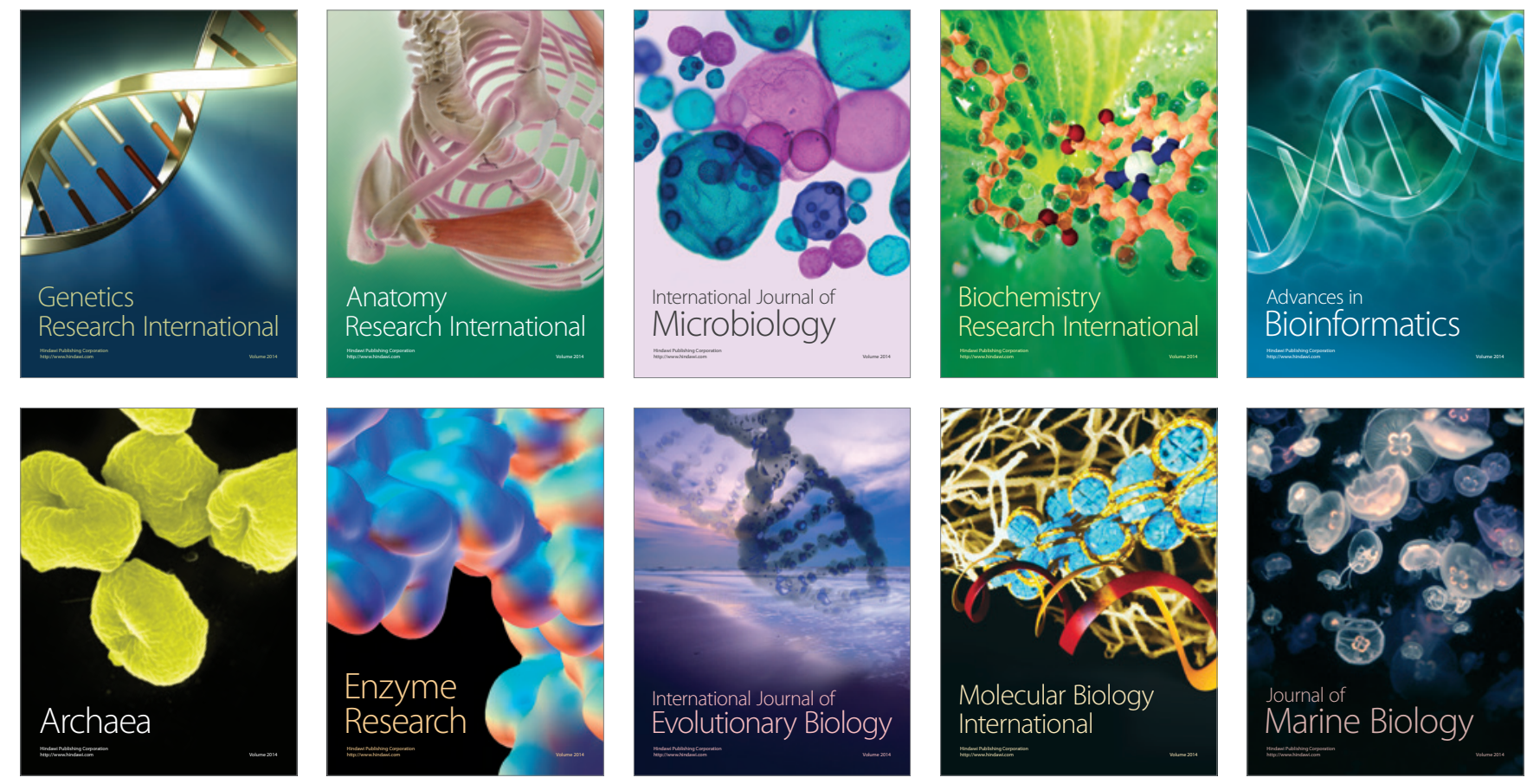